\title{
What Is The Impact Of Case Management On Medical Cost Reduction In Healthcare Insurance Companies?
}

By

Freda Mwamba Brazle, University of Maryland University College

$\mathrm{F}$ or healthcare insurance companies, managing and reducing medical costs is im1 portant to remain viable and meet investor and stakeholder expectations. The need to minimize costs and remain competitive becomes a responsibility for managers who work in healthcare insurance companies. Therefore, managers must contin ually look for methods to identify and implement opportunities that improve case man agement business processes. In this research study, the focus is on the question 'what is the impact of case management on medical cost reduction for healthcare insurance companies? This question is asked within the context of business processes that have manageable variable costs and investigates the relationship between case management processes in healthcare insurance companies and medical costs. The research articles identified to answer the research question and the integrated synthesis of these articles uncover the lack of scholarly research on

how to improve case management processes although evidence suggests that case management does reduce medical costs.

There is an opportunity to provide recommendations on approaches and techniques for improving case management processes to reduce medical costs. Improving case management pro-

Healthcare companies are forced to reduce medical costs to remain viable. This research study explores the relationship between case management and medical costs and identifies recommendations for managers to improve this process. cesses should include quantitative analysis. The recommendation is that as case management processes improve and become more efficient, and when targeted towards the right populations, medical costs for healthcare insurance companies are reduced, thereby improving the financial position of healthcare in surance companies. Therefore, managers who understand and are capable of improving case management processes in healthcare insurance companies contribute more towards the financial position than companies who do not have the right management.

Keywords: Case management, case management processes, efficiency, medical cost reduction, health care insurance

Copyright $\odot$ 2019, Freda Mwamba Brazle. This article is published under a Creative Commons BY-NC license. Permission is granted to copy and distribute this article for non-commercial purposes, in both printed and electronic formats 
Healthcare costs in the United States continue to rise yearly and national health spending is projected to grow at an average rate of 5.5 percent per year from 2017 to 2026 and is predicted to reach $\$ 5.7$ trillion by 2026 (Cuckler et al., 2018). In 2016 there was a six percent increase for health care benefits (By the numbers, 2015) and healthcare costs account for $17.9 \%$ of the gross domestic product in the United States (Centers for Medicare and Medicaid, 2018). With the rising increase in healthcare costs in the United States, healthcare companies are compelled to identify opportunities and implement solutions that reduce medical costs (Bentley, Effros, Palar, \& Keeler, 2008). These increases are significant enough for healthcare insurance companies to identify the cost drivers of business processes and determine approaches to managing them. The need to reduce medical costs is necessary for healthcare insurance companies to remain viable and meet or exceed investor expectations and gain market share. Business expenses are either fixed or variable. Fixed costs such as rent or property taxes cannot be avoided or managed, while variable costs such as medical expenses vary from month to month and can be managed. Healthcare insurance companies have an opportunity to manage variable costs that are driven by case management processes. In this paper, the researcher defines case management as the collaborative process which assesses, plans, implements, coordinates, monitors and evaluates the options and services required to meet an individual's health needs, using communications and available resources to promote quality, cost-effective outcomes (Radzwill, 2002).

Healthcare insurance companies have several different business processes that impact profitability and that need to be effectively managed. Some of these business processes are optimizing networks which include working with value-based providers, total population health management which involves understanding the health of your members, utilization and case management, etc. Of these processes in healthcare insurance companies, utilization management, which is defined as the utilization of resources by Wickizer, John and Feldstein (1989) and care management, which is defined as 'process of care' (Radzwill, 2002) can be assessed and improved by leaders and managers. By doing so, managers and leaders become accountable for understanding their role in creating effective case management processes. They are responsible for identifying opportunities and implementing actionable solutions which will make their healthcare organizations competitive.

\section{Literature Summary}

From the research and review of scholarly articles and gray materials, this study found that case management is used interchangeably with care or disease management. According to Baguhn (2011), case

\section{Methodology}

The University of Maryland College Park (UMUC) OneSearch and ABI/INFORM Complete were the two databases used to perform computer-based literature reviews. Using a search string tailored for the research question, four filters were applied: (1) peer-reviewed scholarly articles, (2) English, (3) USA, and 4) 2000 to current date to focus the number of articles. The search identified 378 scholarly articles that were reviewed for inclusion eligibility, resulting in 24 articles for full-text review. Focusing on the articles most relevant to the research question, nine articles remained for this study. Using the snowballing approach, which identifies additional articles from the reference list of a highly cited article (Goodman et al., 2014) two additional articles were identified from the references and included for a total of 11 articles used for the integrated synthesis.

management was used in the 1980's as an approach to control costs by improving quality and ensuring the appropriate use of hospital resources at the patient's bedside. Other definitions identified by the researcher include its impact on helping increase payment and decrease costs by expediting patient discharge (Baguhn, 2011). Another definition that the researcher encounters is by the Case Management Society of America (CMSA), viz., that case management is the collaborative process which assesses, plans, implements, coordinates, monitors and evaluates options and services to meet an individual's health needs through communication and available resources to promote quality cost effective outcomes (Lobianco, Mills, \& Moore, 1996). Considering these different definitions of case management and the overlap with disease management, the researcher determined that the definition of case management is evolving over time. The researcher suggests that this is likely being driven by enhancements to the case management process and supporting operating models. As several different definitions of case management were encountered such as care management, integrated care coordination, disease management, etc., a decision was made to select a collection of scholarly articles that specifically mentioned case management. This was done to create a boundary on the scope of the research for this paper. The method used to interpret and combine the knowledge from the literature review of the scholarly articles was 'synthesis by integration' which is defined as the review of the collected articles and comparison of evidence involving data collection methods. Based on the weight of evidence of each article and the quality appraisals, the researcher was able to identify common themes and patterns from the 11 articles evaluated. See Appendix for addi- 
Table 1: Common themes from Synthesis of Literature Reviews

\begin{tabular}{|c|c|c|}
\hline Theme & Findings from the Literature & Sources \\
\hline \multirow{5}{*}{$\begin{array}{l}\text { Effective case man- } \\
\text { agement reduces } \\
\text { medical costs } \\
\text { Five of the articles } \\
\text { selected arrive at } \\
\text { conclusions that } \\
\text { there is evidence of } \\
\text { the positive impact } \\
\text { of case manage- } \\
\text { ment on medical } \\
\text { costs. }\end{array}$} & $\begin{array}{l}\text { Determined that a base of evidence exists to support } \\
\text { a premise that community-based case management is } \\
\text { effective because it significantly reduces negative hos- } \\
\text { pital outcomes, especially readmissions and poor cost } \\
\text { effectiveness }\end{array}$ & \multirow[t]{5}{*}{$\begin{array}{l}\text { Joo \& Huber (2014); } \\
\text { Baguhn's (2011); Al- } \\
\text { thaus et al., (2011); } \\
\text { Pottenger et al., } \\
\text { (2016); Shortell et } \\
\text { al., (2009) }\end{array}$} \\
\hline & $\begin{array}{l}\text { Effective case management helps healthcare organi- } \\
\text { zations when interdisciplinary teams were used in the } \\
\text { process by increasing payment and decreasing costs by } \\
\text { expediting patient discharge }\end{array}$ & \\
\hline & $\begin{array}{l}\text { Randomized controlled trials were used and case man- } \\
\text { agement, as the most frequently described intervention, } \\
\text { reduces emergency department use, and improves social } \\
\text { and clinical outcomes }\end{array}$ & \\
\hline & $\begin{array}{l}\text { Care transitions and discharge processes were improved } \\
\text { with patient experiences }\end{array}$ & \\
\hline & $\begin{array}{l}\text { Significant opportunity for improving chronic illness } \\
\text { and public policy will further promote financial re- } \\
\text { wards. }\end{array}$ & \\
\hline \multirow{2}{*}{$\begin{array}{l}\text { Clarification and } \\
\text { importance of roles } \\
\text { and interdisciplin- } \\
\text { ary teams within } \\
\text { case management }\end{array}$} & $\begin{array}{l}\text { The case manager was identified as a vital member of } \\
\text { interdisciplinary teams in health care agencies. }\end{array}$ & \multirow{5}{*}{$\begin{array}{l}\text { Carlson, Cohen, } \\
\text { \& Bice-Stephens } \\
\text { (2014); Peikes et al., } \\
\text { (2009); Martin et al. } \\
\text { (2014); Vaughn et } \\
\text { al., (2014) }\end{array}$} \\
\hline & $\begin{array}{l}\text { The significant role of case managers was described as } \\
\text { including being the patient's key stakeholder in coordi- } \\
\text { nating, collaborating, and communicating health care } \\
\text { needs. }\end{array}$ & \\
\hline \multirow{3}{*}{$\begin{array}{l}\text { The importance } \\
\text { placed on the role } \\
\text { that the case man- } \\
\text { ager plays in the } \\
\text { case management } \\
\text { process is a com- } \\
\text { mon theme in four } \\
\text { of the articles }\end{array}$} & $\begin{array}{l}\text { Discussed opportunities for care managers to improve } \\
\text { case management processes and make enhancements to } \\
\text { the care models used by healthcare companies. }\end{array}$ & \\
\hline & $\begin{array}{l}\text { Recommended training and supervision of behavioral } \\
\text { health providers in care management. }\end{array}$ & \\
\hline & $\begin{array}{l}\text { Information on the reward \& recognition awarded to } \\
\text { employees of high-performance hospitals to drive the } \\
\text { coordination and communication of health discussions. } \\
\text { These are the care managers who have to be proficient at } \\
\text { communication and coordinating }\end{array}$ & \\
\hline $\begin{array}{l}\text { Increasing use of } \\
\text { care management } \\
\text { across different } \\
\text { healthcare organi- } \\
\text { zations }\end{array}$ & $\begin{array}{l}\text { The synthesis of the research presented the increasing } \\
\text { use of care management processes in healthcare compa- } \\
\text { nies which are related to revenues and costs. Highlighted } \\
\text { the value of the benefits of organized delivery systems on } \\
\text { the use of evidence-based chronic care management. }\end{array}$ & $\begin{array}{l}\text { Rodriguez et al., } \\
(2016)\end{array}$ \\
\hline $\begin{array}{l}\text { Lack of quanti- } \\
\text { tative and data } \\
\text { analysis }\end{array}$ & $\begin{array}{l}\text { The researcher looked specifically to find mention of the } \\
\text { quantitative analysis of processes which can be leveraged } \\
\text { to understand case management processes. The scholarly } \\
\text { research identified lacked mention of quantitative anal- } \\
\text { ysis of processes or the opportunities to improve care } \\
\text { management processes either through predictive or data } \\
\text { analysis. The researcher found that there was a gap and } \\
\text { opportunity warranting investigation and exploration to } \\
\text { improve case management processes }\end{array}$ & No references \\
\hline
\end{tabular}


tional detail on the 11 articles. The common themes from the literature are presented in Table 1.

\section{Discussion}

Consistent with the scope of the research question 'what is the impact of case management on medical cost reduction in healthcare insurance companies?' the researcher found that none of the articles that were identified through the search strategy and used in the integrated synthesis explicitly focused on healthcare insurance companies. The context of the evidence-based literature was typically hospital environments. Nevertheless, the general intention of the study was 1) to determine whether case management had an impact on medical costs and 2) the identification of recommendations to improve case management to increase efficiencies of the process with healthcare insurance companies. The researcher used the articles to answer the question with the viewpoint that opportunities to reduce health costs and ensure cost-effective care can be replicated in either environment, whether a hospital or healthcare insurance, and, moreover, that opportunities to control health costs and ensure cost-effective care, access to care, coordinating care services, and improving health outcomes can and should be replicated.

From the appraisal obtained from the scholarly articles, the integrated synthesis suggests that targeted case management will impact and reduce medical costs. There is an opportunity for healthcare insurance companies to focus on the case management business process and highlight the importance of ensuring that case management is targeted toward the right populations. The findings from the research deduce that precedence is given to ensuring role clarification and skilled associates for the case management business process. Importance is also given to interdisciplinary teams.

\section{Implications for Future Research}

The researcher ascertains from scrutinizing the literature that even though there is evidence that case management has an impact on medical costs there is a lack of scholarly research and articles on actionable recommendations for improving or making case management processes more efficient. The observation made from the research study is that further research is needed to provide managers with more scholarly studies on this topic, specifically as it relates to extending case management to healthcare insurance companies and implementing or improving existing case management processes. Managers can benefit from evidence-based documented rec- ommendations to implement improvements to case management which have the potential to reduce medical costs.

\section{Recommendations for Managers}

Based on the integrated synthesis of the research study, healthcare companies should improve their case management processes as they have a positive impact on the reduction of medical expenses. This is the responsibility of case management managers. The researcher identified recommendations based on the results of the common themes of the articles assessed. These recommendations are geared towards managers of healthcare companies and can be customized based on environments. The researcher aligned the identified recommendations to four themes: 1) assess and delegate work, 2) identify and train associates, 3) collaborate and audit work assignments and 4) reward and recognition. The recommendations follow:

\section{1) Assess and delegate work}

Baseline and understand current state case management processes for the specifically identified areas reported as being the top drivers of healthcare insurance company cost for the next five years; cardiovascular, cancer and respiratory illness cases. Determine whether cases are assigned by complexity or by diagnosis to the staff. Document the timeliness and source of cases received and how they are assessed and assigned to the associates who work on the cases. Use data analysis to quantify and prioritize the cases which result in higher costs for the company. Identify those cases from cardiovascular, cancer and respiratory illness which are suited to be managed and addressed more easily than those requiring additional time, resources, or effort. Calculate the cycle time for the processing of cases and identify the measurement systems that are used to determine success for the case management process. Document a foundation of understanding for the people, process and technology that supports the case management process. Validate the accuracy of the current state with key stakeholders: case managers, human resource, finance, managers, leadership, and operations.

\section{2) Identify and train associates}

Assess the staff and determine the current state of the skill set of case managers who work within the business process. Determine relevant and new skills needed to effectively manage cases using newer operational models and quantitative methods such as rising risk members and high-risk scores for car- 
diovascular, cancer and respiratory illness. Provide resources and tools to help identify rising members and identify high-risk scores for those who have not yet started incurring high medical costs but would eventually begin to without the intervention. Determine the gap in skills, including critical thinking and computer and technology skills. Incorporate training that emphasizes a focus on social health determinants of health in case management and data skills. Provide managers specific training on how to support case managers in critiquing and prioritizing the most impactful cases. Engage leadership, management and all employees in driving successful change.

\section{3) Collaborate and audit work assignments}

With the increasing variation in types of cases that are coming through the pipeline, managers should promote more exchange of case information amongst case managers. Create interdisciplinary teams who bring varied skills and experience in assessing and managing the cases. Utilizing data, there is an opportunity to categorize similar cases and find consistent and standard ways that work with certain cases. Promote standard ways for similar processes to benefit expeditious resolution of similar cases. This outweighs researching a unique solution for each case. Create performance dashboards that will allow a visual illustration of the case management process. Explore ways to improve the exchange of patient information with technology and bi-directional exchange between providers or caregivers and case managers which will provide the same information to each party and also allow for more effective and meaningful care discussions.

\section{4) Reward and recognition}

To promote the desired behaviors from associates, there is an opportunity to motivate leaders and managers by assessing and aligning their performance with reward and recognition. With traditional outreach methods not being as effective and the introduction of big data and advances with outreach, associates should be encouraged through reward and recognition to explore new and innovative ways to propagate effective case management.

\section{Risks of Implementation}

There are always risks associated with organizational and business process changes in organizations. Healthcare insurance businesses must manage the risks of making improvements to the case management process associated with resisting change which includes potentially lost productivity, low morale, poor quality, and increased turnover of case management personnel. There are also risks connected to failed implementations of new change initiatives which need to be monitored. It is important to assess and manage employee readiness for change, commitment to change, openness to change and cynicism about organizational change.

\section{Limitations}

There has been a significant amount of research that has been written on case management as it was initially introduced as early as 1863 under the direction of the Board of Charities, a social services case management program. Most of this literature has been curtailed to the hospital environment as opposed to an insurance company which was evident based on the articles selected. The research studies selected for this paper focused on the case management process within healthcare companies in the United States. The researcher came across several hundred articles and synthesized 11 of the most relevant articles for the recommendations and conclusion. The opportunity to identify and include more articles would provide a more accurate current assessment of how effective case management aligns with medical costs in healthcare insurance companies.

Another limitation is that the mixed research studies of the 11 articles included meta-analysis, research data, different population sizes and varying testing methods which can lead to challenging the integrated conclusions and measurements of success. It is also important to note that other factors, such as utilization management, the impact of medical costs and case management cannot be singled out as the singular driver behind reductions of medical expenses.

\section{Conclusions}

There is a positive relationship between effective case management and medical cost reduction. From the integrated assessment of the articles, the researcher found evidence-based methods where case management has made a difference in medical costs. Case management is beneficial to a target population, and not all cases yield a reduction in medical costs. The opportunities to improve case management processes must include a selection of the most impactable cases and assignment of cases to the most qualified associates. The impact on medical costs was more evident where there was a chronic illness that was identified in a timely fashion. 
Gaps that the researcher observed through this synthesis were the absence of studies regarding how to improve the case management process in the healthcare insurance companies. Knowledge of how to improve case management processes would help managers who are required to be competent and drive quantitative process improvements. As new models and discoveries are made in the case management process, employees involved with working the process have to be trained, acquire new skills and work collaboratively to be more productive and meet higher expectations.

Managers need to be motivated and awarded based on their contributions to improving case management. The associates should embrace new approaches and be measured, recognized, rewarded and compensated on the results of their case management processes. Reward and recognition should include collaborative team work. Case management business processes in healthcare insurance companies can be improved to impact medical costs.

\section{References}

*article used in systematic review

*Althaus, F., Paroz, S., Hugli, O., Ghali, W. A., Daeppen, J., Peytremann-Bridevaux, I., \& Bodenmann, P. (2011). Effectiveness of interventions targeting frequent users of emergency departments: A systematic review. Annals of Emergency Medicine, 58(1), 41-52. https://doi.org/10.1016/j. annemergmed.2011.03.007

${ }^{*}$ Baguhn, B. (2011). The case for case management. Healthcare Financial Management: Journal of the Healthcare Financial Management Association, 65(12), 40-43. Retrieved from http:// ezproxy.umuc.edu/login?url=http://search.ebscohost.com/login.asp $\mathrm{x}$ ?direct $=$ true $\& \mathrm{db}=\mathrm{cmed}$ $\mathrm{m} \& A N=22292326 \&$ site $=$ eds-live\&scope $=$ site

Bentley, T. G. K., Effros, R. M., Palar, K., \& Keeler, E. B. (2008). Waste in the U.S. health care system: A conceptual framework. Milbank Quarterly, 86(4), 629-659. https://doi.org/10.1111/j.14680009.2008.00537.x

${ }^{\star}$ Carlson, J., Cohen, R., \& Bice-Stephens, W. (2014). Effectiveness of telebehavioral health program nurse case managers (NCM): Data collection tools and the process for NCM-sensitive outcome measures. U.S.Army Medical Department Journal, 36-45. Retrieved from http:// ezproxy.umuc.edu/login?url=http://search.ebscohost.com/login.aspx?direct $=$ true $\& \mathrm{db}=$ cmed$\mathrm{m} \& \mathrm{AN}=25830797 \&$ site $=$ eds-live $\&$ scope $=$ site

Goodman, J. S., Gary, M. S., \& Wood, R. E. (2014). Bibliographic search training for evidence-based management education: A review of relevant literatures. Academy of Management Learning \&
Education, 13(3), 322-353. https://doi.org/10.5465/ amle. 2013.0188

*Joo, J. Y., \& Huber, D. L. (2014). An integrative review of nurse-led community-based case management effectiveness. International Nursing Review, 61(1), 14-24. https://doi.org/10.1111/inr.12068

Lobianco, M. S., Mills, M. E., \& Moore, H. W. (1996). A model for case management of high cost Medicaid users. Nursing Economics, 14(5), 303. Retrieved from http://ezproxy.umuc.edu/login?url=http:// search.ebscohost.com/login.aspx?direct $=$ true \&d$\mathrm{b}=\mathrm{edb} \& \mathrm{AN}=12305129$ \&site =eds-live \& scope $=$ site

*Martin, M. P., White, M. B., Hodgson, J. L., Lamson, A. L., \& Irons, T. G. (2014). Integrated primary care: A systematic review of program characteristics. Families, Systems \& Health: The Journal of Collaborative Family HealthCare, 32(1), 101-115. https://doi.org/10.1037/fsh0000017

*Peikes, D., Chen, A., Schore, J., \& Brown, R. (2009). Effects of care coordination on hospitalization, quality of care, and health care expenditures among Medicare beneficiaries: 15 randomized trials. Jama, 301(6), 603-618. https://doi.org/10.1001/ jama.2009.126

${ }^{\star}$ Pottenger, B. C., Davis, R. O., Miller, J., Allen, L., Sawyer, M., \& Pronovost, P. J. (2016). Comprehensive unit-based safety program (CUSP) to improve patient experience: How a hospital enhanced care transitions and discharge processes. Quality Management in Health Care, 25(4), 197-202. https:// doi.org/10.1097/QMH.0000000000000106

${ }^{\star}$ Rodriguez, H. P., McClellan, S. R., Bibi, S., Casalino, L. P., Ramsay, P. P., \& Shortell, S. M. (2016). Increased use of care management processes and expanded health information technology functions by practice ownership and Medicaid revenue. Medical Care Research \& Review, 73(3), 308. Retrieved from http://ezproxy.umuc.edu/login?url=http://search.ebscohost.com/login. aspx? direct $=$ true $\& \mathrm{db}=\mathrm{ed}-$ $\mathrm{b} \& \mathrm{AN}=114806189 \&$ site $=$ ed $\mathrm{s}$-live $\&$ scope $=$ site https://doi.org/10.1177/1077558715613233

*Shortell, S. M., Gillies, R., Robinson, J. C., McCurdy, R. K., Siddique, J., Casalino, L. P., \& Rittenhouse, D. (2009). Improving chronic illness care: A longitudinal cohort analysis of large physician organizations. Medical Care, 47(9), 932-939. https:// doi.org/10.1097/MLR.0b013e31819a621a

*Vaughn, T., Koepke, M., Levey, S., Kroch, E., Hatcher, C., Tompkins, C., \& Baloh, J. (2014). Governing board, C-suite, and clinical management perceptions of quality and safety structures, processes, and priorities in U.S. hospitals. Journal of Healthcare Management, 59(2), 111-128. Retrieved from http://ezproxy.umuc.edu/login?url=http:// 
search.ebscohost.com/login.aspx?direct=true\&d$\mathrm{b}=\mathrm{a} 9 \mathrm{~h} \& \mathrm{AN}=95274920$ \& site $=$ ed $\mathrm{s}-$ live $\&$ -

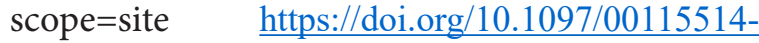
201403000-00006

\section{Review}

This article was accepted under the strict peer review option. For futher details, see the descriptions at:

http://mumabusinessreview.org/peer-review-options/

\section{Author}

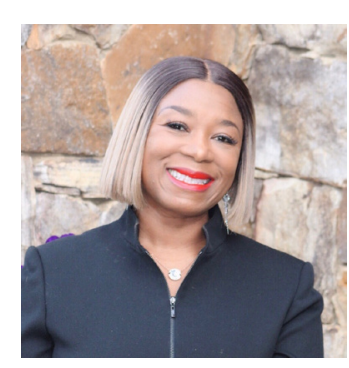

Freda Mwamba Brazle is Chief of Staff for the Chief Clinical Officer of Anthems National Accounts where she has strategic, administrative, financial and program management responsibilities. In addition, Freda serves as Zambia's Country Representative for the Conference of Western Attorneys General where she has facilitated training for over 400 legal professionals in Zambia on transnational crimes. She graduated with a BBA in Management Information Systems and a Master of Science in Accounting from Pace University, New York City. She is a Certified Public Accountant and Master Black Belt in Lean Six Sigma. She is pursuing a Doctorate in Business Administration with a focus on Leadership and Change Management concepts and theories. 